\title{
LOSS OF EGGS ASSOCIATED WITH TUBAL INSEMINATION IN THE RABBIT
}

\author{
C. E. ADAMS \\ Agricultural Research Council, \\ Unit of Reproductive Physiology and Biochemistry, \\ University of Cambridge*
}

(Received 11th September 1972)

\begin{abstract}
Summary. When $0.02 \mathrm{ml}$ rabbit semen containing up to $18 \times 10^{6}$ spermatozoa was deposited into the oviducts of rabbits 0 to $17 \mathrm{hr}$ before ovulation, only 27 to $62 \%$ of the expected number of eggs were recovered approximately $24 \mathrm{hr}$ after the ovulating injection (25 i.u. HCG) was given. Recovery was no better at 17 to $18 \mathrm{hr}$, indicating that the eggs were lost within a few hours of ovulation. Deposition of ram semen and, to a lesser extent, of bull semen was also associated with loss of eggs. Under similar conditions, saline, seminal plasma or dead spermatozoa did not disturb egg recovery. Hence, the loss of eggs was not due to the technique itself disturbing ovum pick-up, except when performed nearer the time of ovulation. Ligating the oviduct near the uterotubal junction did not prevent egg loss.

It was concluded that loss of eggs was caused either directly by capacitated spermatozoa, or indirectly through rupture of the zona pellucida permitting the ooplasm to escape or leucocytes to enter.
\end{abstract}

\section{INTRODUGTION}

Under normal conditions, the efficiency of egg recovery from the excised oviduct of the rabbit is very high, at least up to $60 \mathrm{hr}$ post coitum. For example, Adams \& Chang (1962a) reported a recovery rate of $94 \%$ at 25 to $40 \mathrm{hr}$ post coitum with $76 \%$ (74/97) of the oviducts yielding every egg and only $5 \%$ yielding no eggs whatsoever, whilst Adams (1970) reported rates of $89 \%$ and $96 \%$ shortly after ovulation and at $60 \mathrm{hr}$ post coitum, respectively.

In an experiment concerned with sperm capacitation in which diluted and undiluted semen samples were deposited into the oviducts at various times relative to an ovulating injection, Adams \& Chang (1962b) recovered a higher proportion of eggs from the tubes receiving the diluted semen $(78.6 \%)$ than from those receiving whole semen $(54.9 \%$ ), a finding that was consistent throughout every treatment group; they added that 'no particular reason can be advanced to explain this finding'. Subsequently, Chang (1967) attributed a comparatively low rate of egg recovery following tubal insemination to the technique itself disturbing the reception of eggs by the tubal infundibulum.

* Postal address: 307 Huntingdon Road, Cambridge CB3 0JQ 
Adams (1968, 1969) again recorded reduced rates of egg recovery following both tubal and intraperitoneal insemination, observing that poor egg recovery tended to be associated with the use of larger numbers of spermatozoa. $\mathrm{He}$ concluded that the loss of eggs was due to their early destruction by excess spermatozoa, as suggested earlier by Noyes, Walton \& Adams (1958).

In the pig, too, tubal insemination has been associated with loss of eggs and impaired fertility, but experiments designed to investigate the mode of action proved inconclusive (Hancock \& Buttle, 1968).

The present work was undertaken in an attempt to gain an understanding of the mechanisms that might be responsible for causing the loss of eggs following tubal insemination in the rabbit.

\section{MATERIALS AND METHODS}

A total of ninety-one sexually mature Strain A and Dutch rabbits was used. Several fertile males of the same breeds were available to provide semen which was collected with the aid of an artificial vagina. Normally, ejaculates from four to six males were pooled and three or four does were inseminated at a time. In some experiments, the spermatozoa were concentrated by centrifugation at $1000 \mathrm{rev} / \mathrm{min}$ for $10 \mathrm{~min}$. Seminal plasma was obtained either from vasectomized males or by centrifugation of semen at $3000 \mathrm{rev} / \mathrm{min}$ for $30 \mathrm{~min}$, after which it was carefully separated from the sperm fraction. Samples of dead spermatozoa were obtained by plunging fresh rabbit semen into solid $\mathrm{CO}_{2}$, thawing and repeating the procedure twice. Ram and bull semen was collected with an artificial vagina from our own stock. Sperm density was estimated with a Fuchs-Rosenthal haemocytometer.

Laparotomy was performed under pentobarbitone sodium, $60 \mathrm{mg} / \mathrm{ml}$ (Nembutal; Abbott Laboratories, Ltd) and halothane (Fluothane, I.C.I. Ltd) anaesthesia, and the oviducts were exposed through a mid-line incision. Approximately $0.02 \mathrm{ml}$ semen, seminal plasma or $0.9 \% \mathrm{NaCl}$ solution was deposited into each oviduct through the fimbria by means of a Pasteur pipette connected to a syringe. In certain experiments, one or both oviducts were separated from the uterine horn(s) by double ligation with cotton thread. Generally within $2 \mathrm{hr}$, but occasionally up to $7 \mathrm{hr}$ after insemination, $25 \mathrm{i}$.u. HCG (Lutormone, Burroughs Wellcome) were given intravenously to induce ovulation. In one particular group (Group 6), the injection was not given until 14 to $15 \mathrm{hr}$ after insemination.

With the exception of Group 2B (see below), autopsy was performed 24 to $26 \mathrm{hr}$ after injection of HCG, i.e. approximately 14 to $16 \mathrm{hr}$ after ovulation. The animals were killed by the rapid intravenous injection of pentobarbitone sodium, $200 \mathrm{mg} / \mathrm{ml}$ (Expiral, $1.5 \mathrm{ml}$; Abbott Laboratories Ltd) and were then bled for a few minutes from the severed jugular veins before excision of the whole genital tract. After carefully counting the ovulation points, the tubes were prepared and flushed with $2 \mathrm{ml} 0.9 \% \mathrm{NaCl}$ solution. The flushings were examined immediately for the presence of eggs and whenever fewer than expected were recovered the tubes were re-flushed; finally, careful search was made for egg remnants. Eggs recovered 24 to $26 \mathrm{hr}$ after HCG were examined 
microscopically for evidence of fertilization, i.e. cleavage and presence of spermatozoa, whereas those recovered within $20 \mathrm{hr}$ of HCG injection were fixed and stained for examination (Chang, 1952).

Details of the various treatment groups are given below.

Group 1: Semen deposited into both oviducts.

Group 2: Semen deposited into one oviduct, the other left untouched. (A) Autopsy $24 \mathrm{hr}$ after HCG and (B) autopsy 17 to $18 \mathrm{hr}$ after HCG.

Group 3: Semen deposited into one oviduct, seminal plasma into the other.

Group 4: Seminal plasma deposited into one oviduct; $0.9 \% \mathrm{NaCl}$ into the other.

Group 5: Dead spermatozoa in seminal plasma deposited into both oviducts. Group 6: Semen (A) or saline (B) deposited into both oviducts.

Group 7: Ram semen (A) or bull semen (B) deposited into both oviducts.

Group 8: As Group 2, except that the oviduct receiving semen was ligated (A) or the untreated oviduct was ligated (B), or both oviducts were ligated either $1 \mathrm{hr}(\mathrm{C})$ or 6 to $7 \mathrm{hr}(\mathrm{D})$ before HCG.

Additionally, thirteen does were treated like those in Group 1, except that they were kept to term. Each oviduct received 5 to $10 \times 10^{6}$ spermatozoa $\frac{1}{2}$ to 3 hr before HCG. Pregnancy was diagnosed by palpation on Day 10 .

After this series of experiments was completed, it was observed for the first time that eggs can be 'destroyed' in the oviducts as a result of massive sperm penetration following intravaginal insemination. Details of the animal involved, a sexually mature Dutch doe, are as follows: the doe was pre-treated with a horse anterior pituitary preparation to induce superovulation (Adams, 1971) and artificially inseminated with $0.7 \mathrm{ml}$ freshly collected semen containing $259 \times 10^{6}$ spermatozoa/ml. Exactly $2 \mathrm{hr}$ later, 30 i.u. HCG were injected intravenously and, after an interval of $4 \mathrm{hr}$, the left oviduct was sectioned near its junction with the uterus (Adams, 1956). Egg recovery was carried out at autopsy $29 \frac{1}{4} \mathrm{hr}$ after HCG.

\section{RESULTS}

The results, which are expressed in terms of (a) the proportion of eggs recovered and fertilized and (b) the proportion of tubes yielding minimal $(0 \%)$ or maximal $(100 \%)$ proportions of eggs, are presented in Table 1. Details of the numbers of does used, the numbers of spermatozoa inseminated and the interval from insemination to the injection of HCG also appear in Table 1.

Following deposition of semen into both oviducts of nine rabbits (Group 1) 10 to $14 \mathrm{hr}$ before ovulation, only $33 \%$ of the eggs were subsequently recovered. Recovery failed completely in six of the eighteen oviducts and recovery was complete in only two cases.

The egg recovery rate in does killed $24 \mathrm{hr}$ after HCG (Group 2A) was reduced to $62 \%$ in the tubes that had received semen; it was also reduced, to $73 \%$, in the untreated tubes. In Group 2B does, which were killed nearer the time of ovulation, the picture was almost identical. It appears, therefore, that the eggs were 'lost' within a few hours of ovulation, after which there was no 


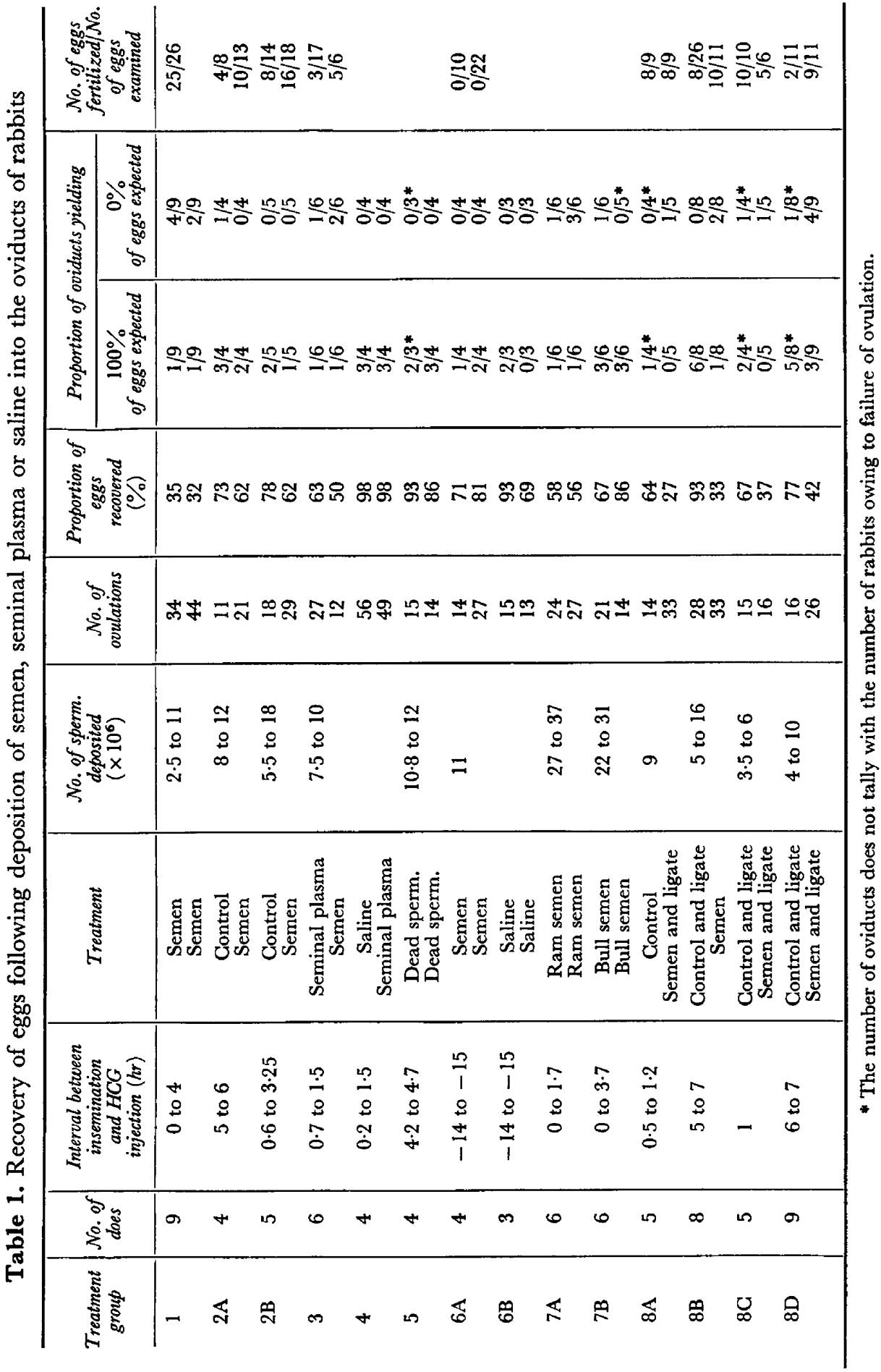


further loss. The finding that of the fourteen eggs recovered from the tubes which were not inseminated, eight were fertilized proves that sperm migration occurred either across the body cavity or through the genital tract.

In Group-3 does, the rate of egg recovery was again reduced, not only in the tubes receiving semen but also in those receiving only seminal plasma. Once again there was evidence of sperm migration both in the recovery of motile spermatozoa in the flushings and of some fertilized eggs.

In Group 4, saline was deposited in one oviduct and seminal plasma in the other, thus avoiding the presence of spermatozoa. Because the rate of egg recovery was now almost maximal, it could be concluded that the technique itself was not responsible for causing the eggs' disappearance. Further, because the seminal plasma did not interfere with egg recovery, the other major component of semen, spermatozoa, was implicated.

Following the deposition of dead spermatozoa suspended in seminal plasma (Group 5), egg recovery was within the normal range, averaging $91 \%$. It appeared, therefore, that, to cause the loss of eggs, the spermatozoa needed to be living.

In all of the preceding experiments, the semen was deposited sufficiently long before ovulation to satisfy the requirements of the spermatozoa to undergo capacitation in the oviduct, as determined by Adams \& Chang (1962b). Since, by definition, spermatozoa require to undergo capacitation before they can penetrate the zona pellucida, it was of interest to establish how egg recovery would be affected if the spermatozoa were not allowed enough time to become capacitated. Thus, when insemination took place 4 to $5 \mathrm{hr}$ after ovulation and egg recovery was performed $8 \frac{1}{2}$ to $10 \mathrm{hr}$ after insemination, the rate of egg recovery $(78 \%$ ) was below normal with only three oviducts out of eight yielding their full complement of eggs (Group 6A). This suggested that even uncapacitated or partially capacitated spermatozoa could cause the loss of eggs. However, in a control experiment (6B), in which a similar volume of saline was deposited into the oviducts, the egg recovery rate was also depressed, showing that manipulation alone when performed after ovulation, could account for this particular result.

In order to test whether the effect was confined to rabbit spermatozoa, either ram or bull semen was deposited into the oviducts (Groups 7A and B). Ram semen, in particular, was associated with a significant reduction in egg recovery rate, which affected virtually every oviduct. With bull semen, the effect was less marked and more variability existed both between and within rabbits: in $50 \%$ of the oviducts, every egg was recovered. Examples of eggs recovered from tubes inseminated with ram or bull semen are shown in Pl. 1, Figs 1 and 2.

The preceding experiments did not entirely eliminate the possibility that the tubal deposition of spermatozoa was in some way influencing egg transport, causing losses to occur through accelerated transport into the uterus. By ligating the oviducts at the time of insemination, any such egg movement could be prevented, and the spermatozoa could be confined to the oviducts. In the first two experiments in this series (Group 8), semen was deposited into one oviduct and access to the uterus was prevented by sectioning the oviduct near the tubo- 
uterine junction, ipsilaterally in one group (A) and contralaterally in another (B). In both groups, egg recovery from the inseminated oviducts was very low, i.e. $27 \%$ and $33 \%$, respectively. However, ligation did seem to affect the result in the case of the oviducts which were not inseminated, the ligated ones yielding $93 \%$ of the eggs compared with only $64 \%$ from the unligated ones. Because these two groups were not strictly comparable owing to a difference in the time of ovulation relative to insemination, the experiment was repeated and modified to include the ligation of both oviducts (Groups $8 \mathrm{C}$ and D). Once again the proportion of eggs recovered from the inseminated oviducts was low $(37 \%$ and $42 \%$ ) and it was depressed $(67 \%$ and $77 \%$ ) on the side which was not inseminated. This experiment proves that the eggs were not being lost by escaping into the uterus.

\section{Fertilization}

Throughout the various treatment groups, the level of fertilization was high following intratubal insemination, and frequently excessively large numbers of spermatozoa had penetrated the zona pellucida (Pl. 1, Fig. 3). No cases of polyspermic fertilization, however, were seen among the eggs examined at pronuclear stages, though the presence of up to eighteen extra spermatozoa was recorded. Fertilized eggs were also recovered from the tubes which were not inseminated (Groups 2, 3 and 8) (Pl. 1, Fig. 4). Fertilization presumably followed migration of spermatozoa across the body cavity due to leakage from the inseminated oviduct.

A consistent incidental finding was the reduction in the thickness of the mucin layer on eggs recovered from inseminated oviducts (compare Pl. 1, Figs 3 and 4).

\section{Pregnancy rate and litter size following intratubal insemination}

Of the thirteen does that were kept to term, only four became pregnant and these produced 1, 2, 4 and 9 young: the breed average is $7 \cdot 9$, range 1 to 13 .

\section{EXPLANATION OF PLATE 1}

FIG. 1. Rabbit eggs recovered $23 \mathrm{hr}$ after deposition of ram semen into the oviduct. Many spermatozoa are present on the zona pellucida. $\times 170$.

FIG. 2. Rabbit eggs recovered $27 \mathrm{hr}$ after deposition of bull semen into the oviduct. Some spermatozoa can be seen lying on the zona pellucida, which is bounded by a thin layer of mucin. $\times 225$.

FIGs 3 and 4. Morulae recovered from the left and right oviduct of a rabbit which was treated with HCG $43 \mathrm{hr}$ before autopsy. Five hours before the HCG, $10 \times 10^{6}$ spermatozoa were deposited into the left oviduct, which was ligated near the uterotubal junction. Note the excessive number of spermatozoa in Fig. 3, and the relative absence of mucin $(15 \mu \mathrm{m})$ compared with Fig. $4(71 \mu \mathrm{m})$. Fig. 3, $\times 240$; Fig. 4, $\times 170$.

FIGs 5 and 6 . The remains of eggs recovered from one oviduct of a rabbit which was treated with HCG $2 \mathrm{hr}$ after intravaginal insemination. Abnormally large numbers of spermatozoa are present and in Fig. 6, where the ooplasm is missing, there are also some leucocytes. There is no mucin layer. Fig. 5, × 210; Fig. $6, \times 165$.

FIG. 7. Group of fifteen four-cell eggs recovered from the other oviduct of the rabbit referred to above (Figs 5 and 6 ). The oviduct had been sectioned at the uterotubal junction $4 \mathrm{hr}$ after insemination. Note the almost total absence of spermatozoa in the zona pellucida and perivitelline space. A thin layer of mucin is present on the eggs. $\times 65$.

Fig. 8. The remains of an egg recovered from the oviduct of a rabbit which had received rabbit spermatozoa $24 \mathrm{hr}$ earlier. The zona pellucida is ruptured and leucocytes have gained entry. $\times 210$. 
PI. IIE

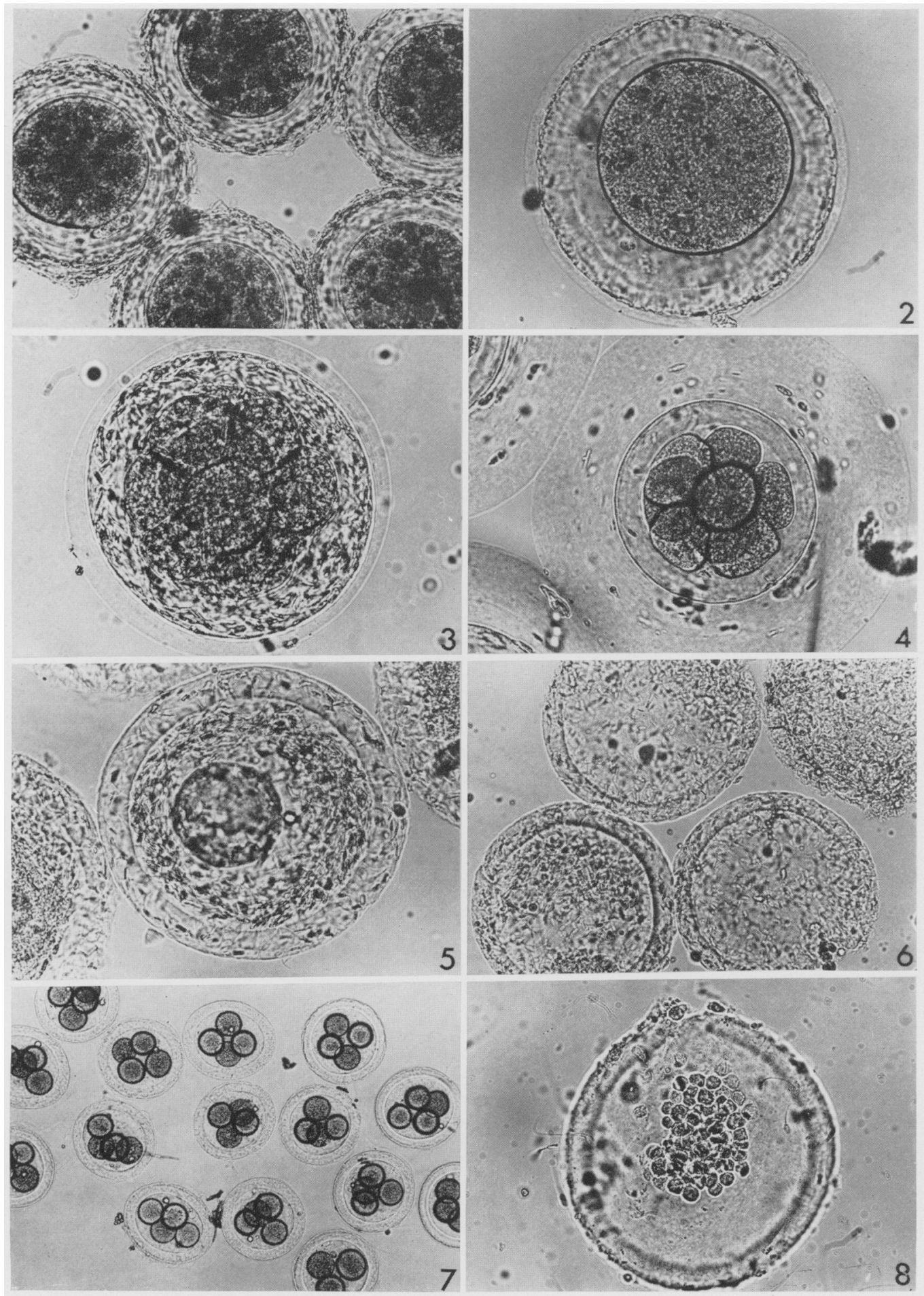

(Facing p. 410 


\section{Destruction of eggs following intravaginal insemination}

At autopsy $29 \frac{1}{4} \mathrm{hr}$ post coitum, fifteen and fourteen ovulation points were recorded on the left and right ovaries, respectively, and corresponding numbers of eggs were recovered. The right control oviduct yielded a variety of eggs which included five in which no ooplasm or blastomeres were present ('empty' zonae), three one-cell eggs, two two-cell eggs, three four-cell eggs, and one egg containing what appeared to be the remaining blastomere of a four-cell stage. All of these eggs, including the empty zonae and the one-cell stages, contained extraordinarily large numbers of spermatozoa within the zona pellucida and perivitelline space (Pl. 1, Figs 5 and 6). By contrast, the fifteen four-cell eggs recovered from the sectioned oviduct contained almost no extra spermatozoa (Pl. 1, Fig. 7). The zonae of the 'sperm-rich' eggs were very easily disrupted by mechanical means.

\section{DISCUSSION}

In earlier work on the rabbit (Adams \& Chang, 1962b; Chang, 1967; Adams, 1968, 1969), it was observed that, following the deposition of semen into the oviduct, egg recovery was adversely affected but the underlying mechanism was not elucidated. The present series of experiments indicates that capacitated spermatozoa are responsible for causing the loss of eggs rather than some other component of the semen.

Compelling evidence against interference with the ovum pick-up mechanism (Chang, 1967) being involved is provided by the fact that (a) no significant loss of eggs occurred from treated tubes unless living spermatozoa were deposited, (b) loss of eggs also occurred from control untreated tubes contralateral to those receiving semen, and (c) egg recovery was also impaired following intraperitoneal insemination which does not involve any direct disturbance of the oviduct (Adams, 1969). Another possibility, i.e. accelerated transport of eggs to the uterus, is discounted because the loss of eggs was equally great in ligated tubes.

Because fragments of eggs were rarely recovered, it is difficult to be precise concerning the manner in which the eggs may have been destroyed. It is known that the sperm acrosome contains an enzyme that is capable of lysing the egg membranes and ooplasm (Srivastava, Adams \& Hartree, 1965; Stambaugh \& Buckley, 1968). If excessive numbers of spermatozoa gain entry to the perivitelline space, it is conceivable that the ooplasm may be destroyed in situ. Alternatively, if the zona pellucida is ruptured, the ooplasm may escape to undergo destruction in the oviduct, not necessarily by spermatozoa. Naked blastomeres transferred to the oviduct are recoverable for only a few hours in the rabbit (Moore, Adams \& Rowson, 1968) and mouse (Bronson \& McLaren, 1970; Modlinski, 1970), even in the absence of spermatozoa. Another possibility which was postulated earlier by Moore et al. (1968) and for which evidence is presented is that leucocytes, whose numbers are greatly increased following tubal insemination, may enter and destroy the egg (Pl. 1, Fig. 8). The essential primary rôle of the spermatozoa is indicated by the fact that egg recovery from ligated oviducts which are not inseminated and which also contain elevated 
numbers of leucocytes, has been shown to be within the normal range (Adams, 1973).

Before spermatozoa can penetrate the zona pellucida, they require to undergo capacitation, a process that takes about $10 \mathrm{hr}$ in the oviduct (Adams \& Chang, 1962b). It is puzzling, therefore, that the deposition of ram or bull spermatozoa was also associated to a varying extent with the loss of eggs despite the fact that there is no evidence that the spermatozoa of these species can either undergo capacitation in the oviduct of the rabbit or penetrate rabbit eggs. It may be recalled, however, that preparations have been obtained from ram and bull spermatozoa which are capable of lysing the zona pellucida of the rabbit egg in vitro (Srivastava et al., 1965).

The degree of variation recorded in the proportion of eggs recovered (27 to $62 \%$ ) from tubes that had received semen is not unexpected in view of the variability in the numbers of spermatozoa inseminated, time of insemination relative to ovulation, and size and capacity of the oviducts. The observation that, within animals, some eggs could not be accounted for whilst others remained intact in spite of coming into contact with, or even being penetrated by, hundreds of spermatozoa (PI. 1, Fig. 3) is noteworthy; currently no better explanation can be offered than variation in the condition of the zona pellucida. Between species, the zona pellucida is known to vary in its resistance to dissolution by certain enzymes, e.g. pronase, and it is possible that within both species and individual animals the character of the zona pellucida may vary.

In confirmation of an earlier report (Adams \& Chang, 1962b), no increase was found in the incidence of polyspermy in eggs fertilized following tubal deposition of abnormally high numbers of spermatozoa, though extra spermatozoa were frequently seen. This supports the view that in freshly ovulated eggs the block to polyspermy is highly effective whereas, in aged eggs, the frequency of polyspermic fertilization is significantly increased (Austin \& Braden, 1953). Braden (1954) established that there is a great reduction in the numbers of spermatozoa as they traverse the genital tract and concluded that this had significance in reducing the risk of polyspermy. The present observations suggest that it could have additional significance, especially in species like the rabbit where the spermatozoa await the eggs, which are then fertilized before they age.

The abnormally high numbers of spermatozoa present in the eggs depicted in Pl. 1, Figs 5 and 6 could be directly related to the fact that ovulation was delayed by $2 \mathrm{hr}$, thereby allowing more time for the capacitation process. The quantitative aspects of state of capacitation of a population of spermatozoa and penetration of eggs relative to the time of ovulation merit systematic investigation.

ACKNOWLEDGMENTS

I am indebted to Mr M. L. Norris for technical assistance, Dr G. Polge for help with examination of the pronuclear stages, and Dr H. M. Dott for arranging the supply of bull and ram semen.

\section{REFERENCES}

Adams, C. E. (1956) A study of fertilization in the rabbit; the effect of post-coital ligation of the Fallopian tube or uterine horn. F. Endocr. 13, 296. 
ADAms, C. E. (1968) Fertilizing capacity of rabbit spermatozoa deposited in the vagina, Fallopian tubes or peritoneal cavity. Proc. 6th int. Congr. Anim. Reprod. and A.I., Paris, 1, 31 .

Adams, C. E. (1969) Intraperitoneal insemination in the rabbit. 7. Reprod. Fert. 8, 333.

ADAMs, C. E. (1970) Ageing and reproduction in the female mammal with particular reference to the rabbit. 7. Reprod. Fert. Suppl. 12, 1.

Adams, C. E. (1971) The fate of fertilized eggs transferred to the uterus or oviduct during advancing pseudopregnancy in the rabbit. F. Reprod. Fert. 26, 99.

Adams, C. E. (1973) The development of rabbit eggs in the ligated oviduct, and their viability after retransfer to recipient rabbits. F. Embryol. exp. Morph. 29, 133.

Adams, C. E. \& Chang, M. C. (1962a) The effect of delayed mating on fertilization in the rabbit. 7 . exp. Zool. 151, 155.

Adams, C. E. \& Chang, M. C. (1962b) Capacitation of rabbit spermatozoa in the Fallopian tube and in the uterus. F. $\exp$. Zool. 151, 159.

Austin, C. R. \& BrAden, A. W. H. (1953) An investigation of polyspermy in the rat and rabbit. Aust. F. biol. Sci. 6, 674.

Braden, A. W. H. (1954) Distribution of sperms in the genital tract of the female rabbit after coitus. Aust. F. biol. Sci. 6, 693.

Bronson, R. A. \& McLaren, A. (1970) Transfer to the mouse oviduct of eggs with and without the zona pellucida. 7. Reprod. Fert. 22, 129.

Chang, M. C. (1952) Fertilizability of rabbit ova and the effects of temperature in vitro on their subsequent fertilization and activation in vivo. F. exp. Zool. 121, 351.

ChANG, M. C. (1967) Effects of progesterone and related compounds on fertilization, transportation and development of rabbit eggs. Endocrinology, 81, 1251.

Hancock, J. L. \& Buttre, H. L. (1968) Tubal transport and fertilization of ova in gonadotrophintreated pigs. F. Reprod. Fert. 16, 261.

Moduinski, J. A. (1970) The role of the zona pellucida in the development of mouse eggs in vitro. $\mathcal{J}$. Embryol. exp. Morph. 23, 539.

Moore, N. W., AdAms, C. E. \& Rowson, L. E. (1968) Developmental potential of single blastomeres of the rabbit egg. 7. Reprod. Fert. 17, 527.

Noyes, R. W., Walton, A. \& Adams, C. E. (1958) Capacitation of rabbit spermatozoa. J. Endocr. 17, 374.

Srivastava, P. N., Adams, C. E. \& Hartree, E. F. (1965) Enzymic action of acrosomal preparations on the rabbit ovum in vitro. F. Reprod. Fert. 10,61.

Stambaugh, R. \& Buckley, J. (1968) Zona pellucida dissolution enzymes of the rabbit sperm head. Science, $\mathcal{N}$. Y. 161, 585 . 